Supplement of Atmos. Chem. Phys., 20, 5355-5372, 2020

https://doi.org/10.5194/acp-20-5355-2020-supplement

(C) Author(s) 2020. This work is distributed under

the Creative Commons Attribution 4.0 License.

(c) (i)

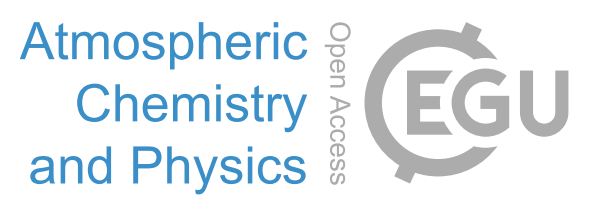

Supplement of

\title{
Exploring wintertime regional haze in northeast China: role of coal and biomass burning
}

\section{Jian Zhang et al.}

Correspondence to: Weijun Li (liweijun@zju.edu.cn)

The copyright of individual parts of the supplement might differ from the CC BY 4.0 License. 


\section{ECD vs. ESD}
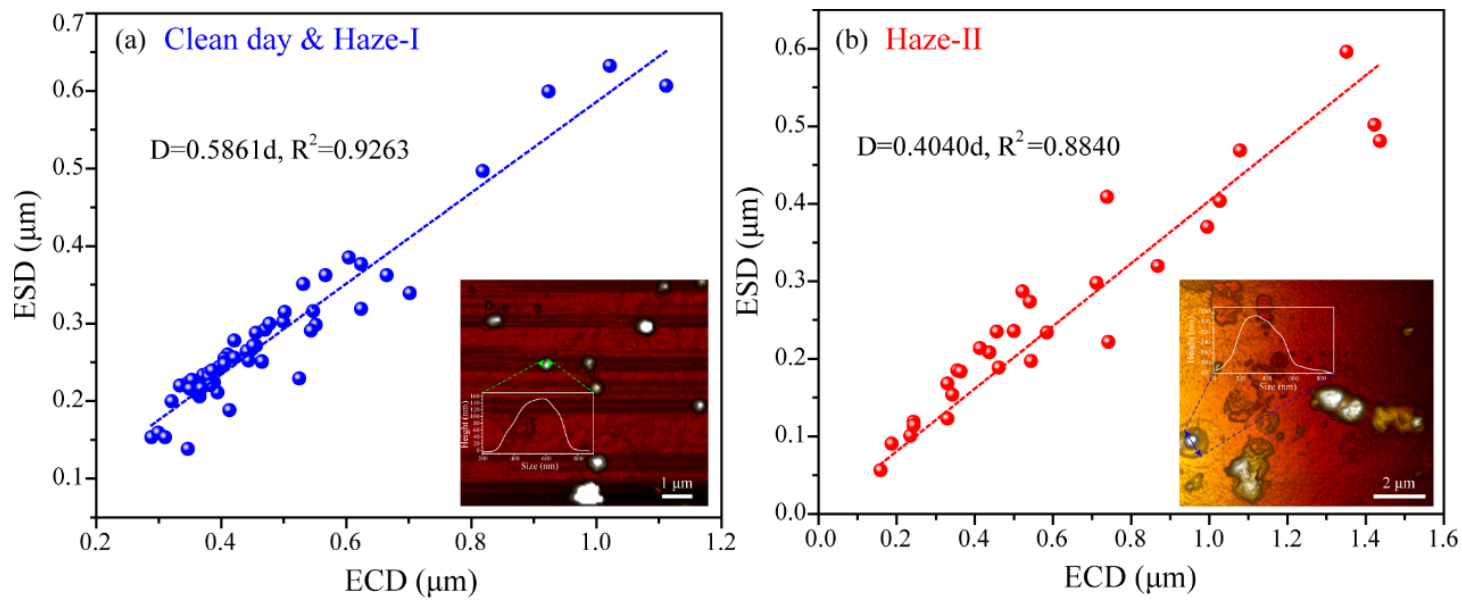

Figure S1. Linear correlations between equivalent circle diameter (ECD, d) and equivalent sphere diameter (ESD, D) and atomic force microscopy (AFM) images of individual particles during the clean day and Haze-I (a) and Haze-II (b).

\section{Concentrations of $\mathbf{P M}_{2.5}$ and its chemical compositions}

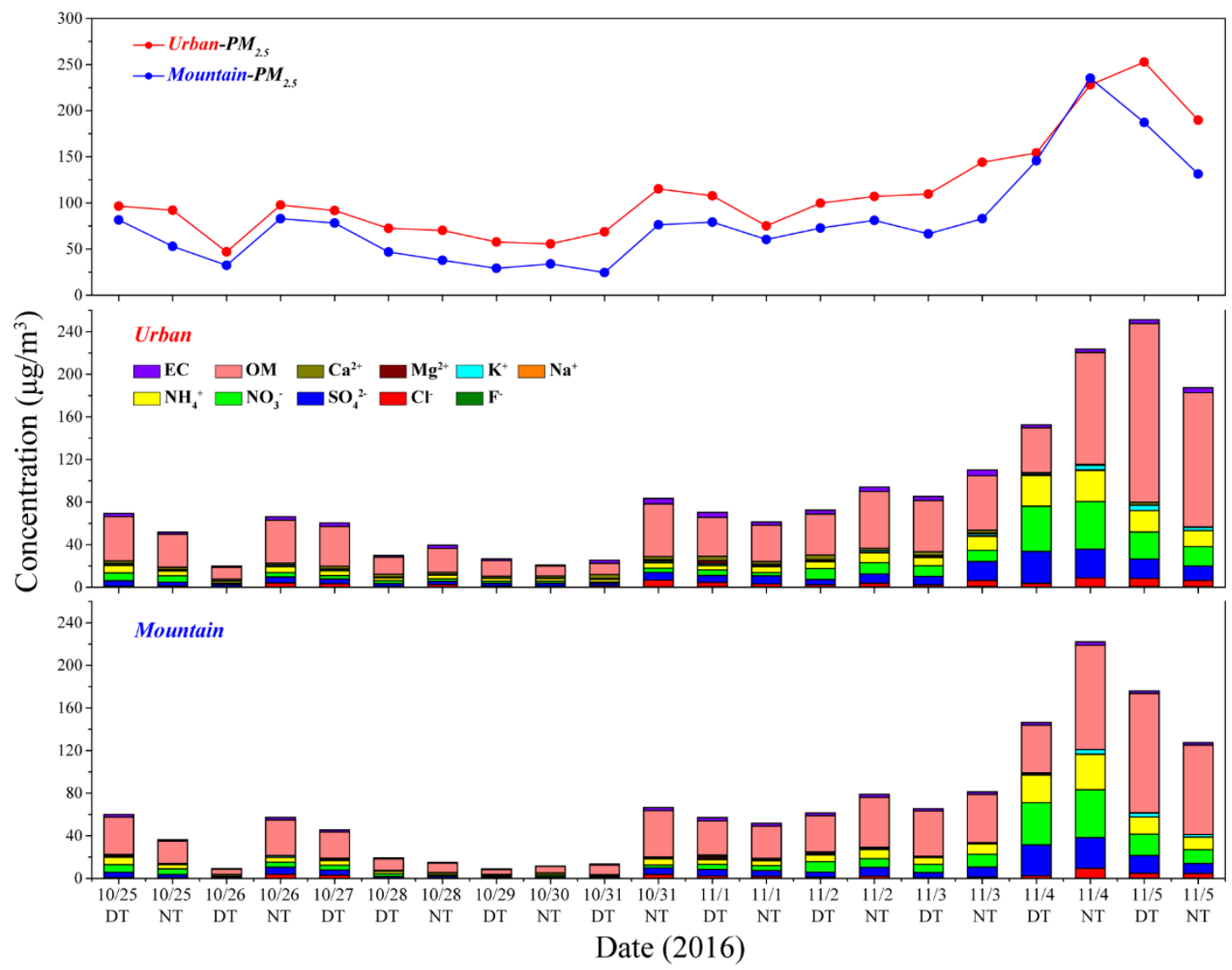

Figure S2. Time series of mass concentrations of $\mathrm{PM}_{2.5}$ and its chemical compositions at the urban 
and mountain sites during the sampling period.

\section{Air quality map in Northeast China}

Figure S3 shows three typical air quality maps of Northeast China on 31 October, 3 November, and 4 November, suggesting that a regional haze pollution occurred in Northeast China during 31 October-5 November.

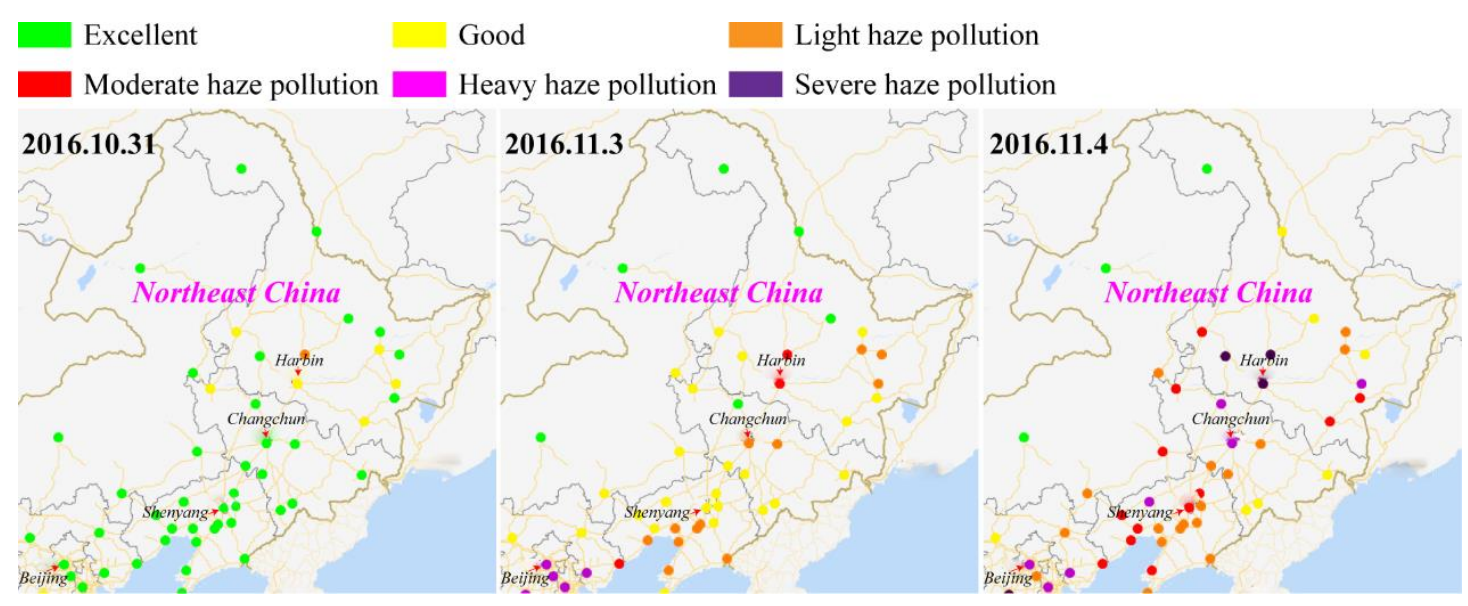

Figure S3. Daily air quality in many cities in Northeast China on 31 October, 3 November, and 4 November 2016 during the sampling period. The data are derived from China's Air Quality Online Monitoring and Analysis Platform (https://www.aqistudy.cn/), while the maps are from $\mathbb{C}$ Baidu and (C) OpenStreetMap contributors 2019 distributed under a Creative Commons BY-SA License (https://www.openstreetmap.org/).

\section{Meteorological fields}




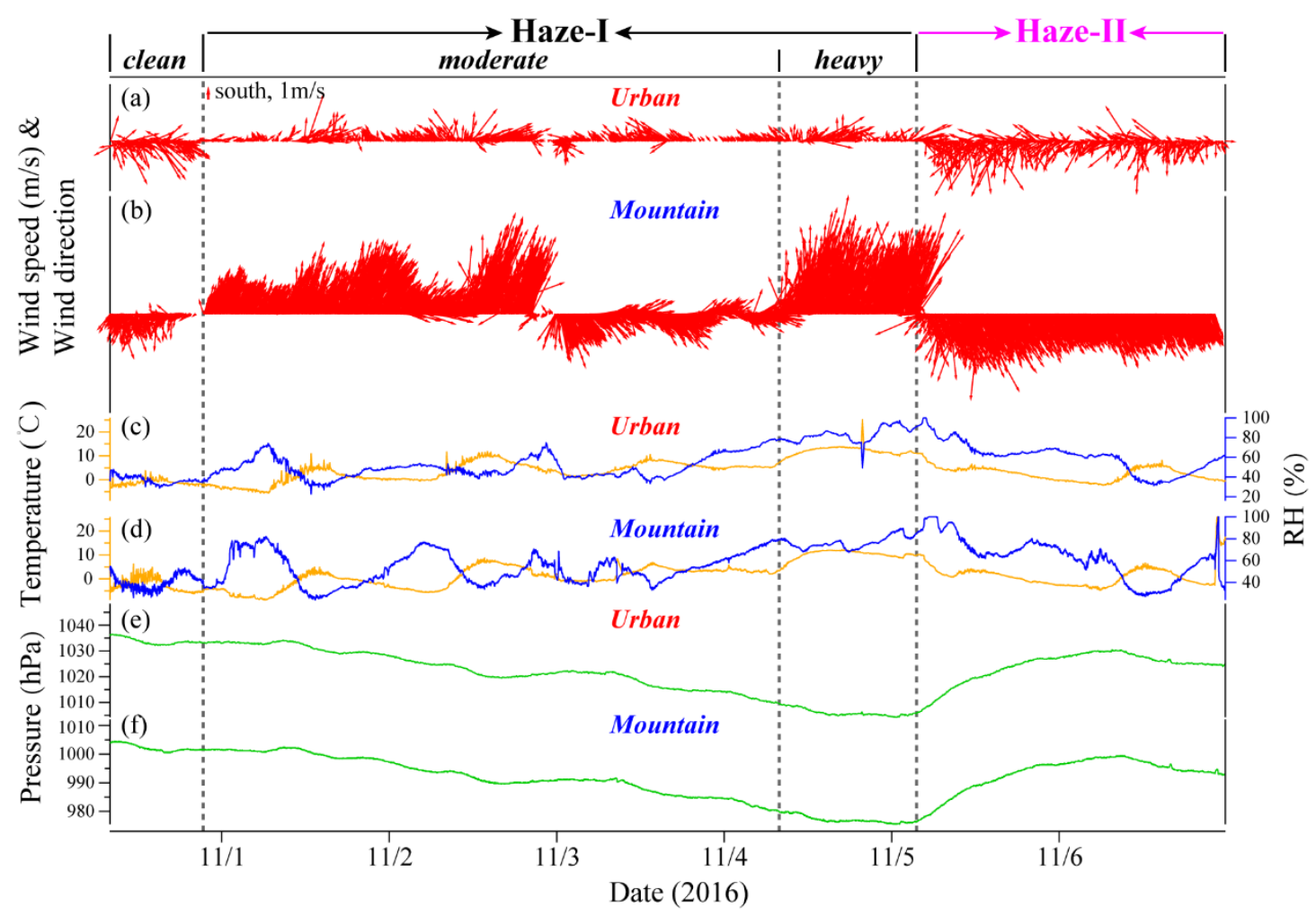

Figure S4. Time series of meteorological parameters at the urban and mountain sites from 31 October to 6 November 2016: (a-b) wind speed and wind direction; (c-d) temperature and relative humidity (RH); (e-f) pressure.

\section{Air mass backward trajectories and CWT plots of $\mathbf{P} \mathbf{M}_{2.5}$}



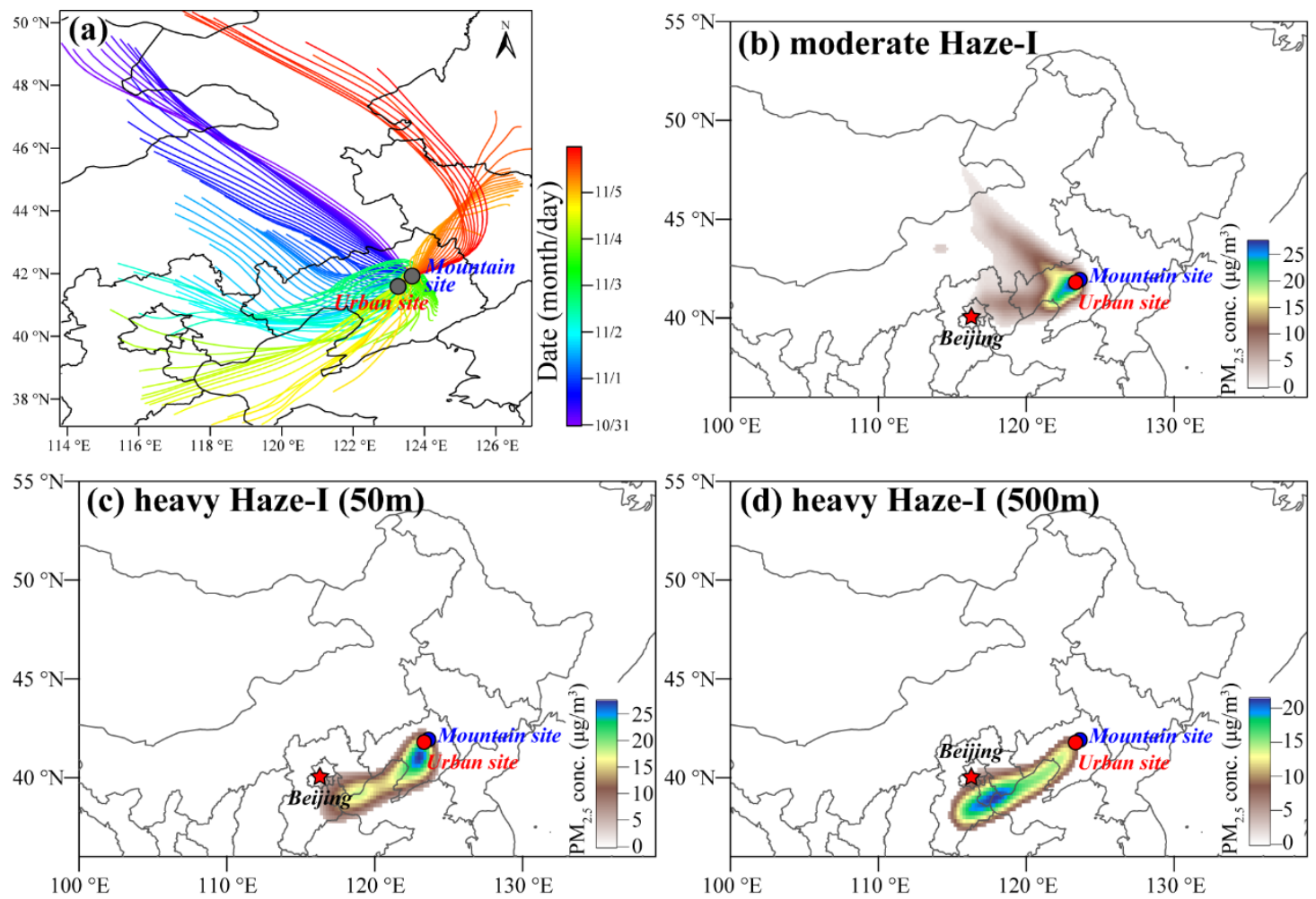

Figure S5. (a) 24-h air mass backward trajectories on $500 \mathrm{~m}$ height before arriving at Shenyang during 31 October-5 November. Concentration-weighted trajectory (CWT) plots of $\mathrm{PM}_{2.5}$ at the urban and mountain sites during the Haze-I event: (b) moderate Haze-I on 500 m height; (c-d) heavy Haze-I on $50 \mathrm{~m}$ and $500 \mathrm{~m}$ heights.

\section{Concentrations of trace gases}




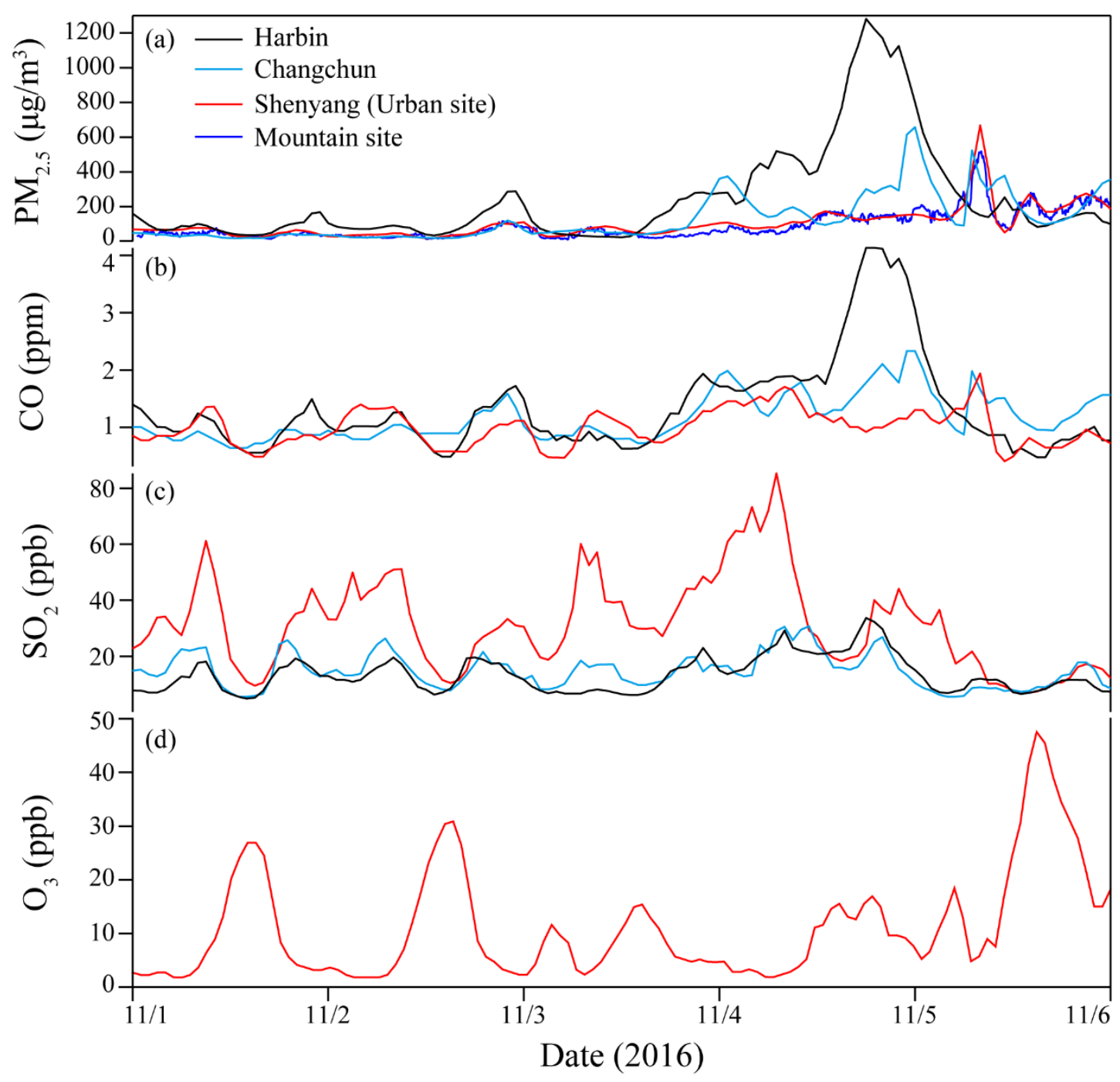

Figure S6. Time series of $\mathrm{PM}_{2.5}$ and three trace gases (i.e., $\mathrm{CO}, \mathrm{SO}_{2}$, and $\mathrm{O}_{3}$ ) in Harbin city, Changchun city, Shenyang city (the urban site), and the mountain site from 1 to 5 November 2016: (a) $\mathrm{PM}_{2.5}$; (b) $\mathrm{CO}$; (c) $\mathrm{SO}_{2}$; (d) $\mathrm{O}_{3}$. These data have been obtained from China's Air Quality Online Monitoring and Analysis Platform, except for the $\mathrm{PM}_{2.5}$ at the mountain site.

\section{Size distribution of individual particles}


(a) Urban

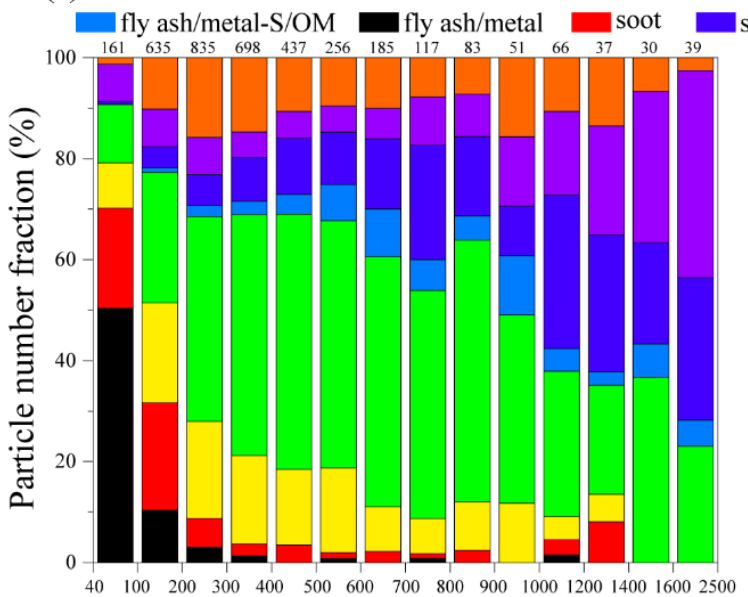

(b) Mountain

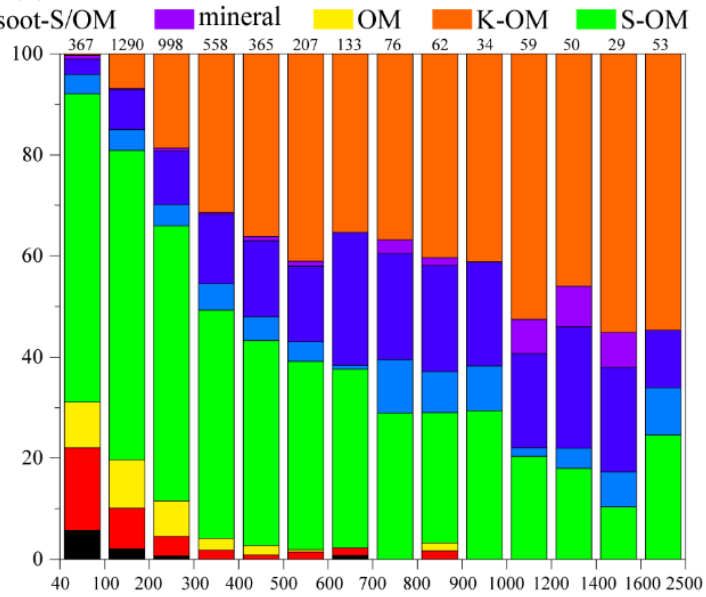

Size bin $(\mathrm{nm})$

Figure S7. Size distribution of individual particles at (a) the urban site and (b) the mountain site. Analyzed particle numbers are listed on the top of each rectangle.

\section{Comparison on $\mathbf{P M}_{2.5}$ data}

Table S1. Comparison on $\mathrm{PM}_{2.5}$ mass concentrations from quartz filters and nearby monitoring station.

\begin{tabular}{cccc}
\hline Date & Urban site $\left(\mu \mathrm{g} / \mathrm{m}^{3}\right)$ & Nearby monitoring station $\left(\mu \mathrm{g} / \mathrm{m}^{3}\right)$ & Deviation \\
\hline $10 / 31 \mathrm{DT}$ & 69 & 59 & $14 \%$ \\
$10 / 31 \mathrm{NT}$ & 115 & 104 & $10 \%$ \\
$11 / 1 \mathrm{DT}$ & 108 & 94 & $13 \%$ \\
$11 / 1 \mathrm{NT}$ & 75 & 65 & $13 \%$ \\
$11 / 2 \mathrm{DT}$ & 100 & 91 & $9 \%$ \\
$11 / 2 \mathrm{NT}$ & 107 & 96 & $10 \%$ \\
$11 / 3 \mathrm{DT}$ & 110 & 98 & $11 \%$ \\
$11 / 3 \mathrm{NT}$ & 144 & 132 & $8 \%$ \\
$11 / 4 \mathrm{DT}$ & 154 & 141 & $8 \%$ \\
$11 / 4 \mathrm{NT}$ & 228 & 211 & $7 \%$ \\
$11 / 5 \mathrm{DT}$ & 253 & 232 & $8 \%$ \\
$11 / 5 \mathrm{NT}$ & 190 & 165 & $13 \%$ \\
\hline
\end{tabular}




\section{9. $\mathrm{OC} / \mathrm{EC}$ ratios}

Table S2. The ratios of OC/EC in Northeast China and North China Plain (NCP) during winter haze days.

\begin{tabular}{cccc}
\hline Sampling site & Period & OC/EC & References \\
\hline Urban site & $31 / 10-4 / 11 / 2016$ (Haze-I) & $8.0 \pm 1.5$ & This study \\
Urban site & $4-5 / 11 / 2016$ (Haze-II) & $25.4 \pm 5.9$ & This study \\
Mountain site & $31 / 10-4 / 11 / 2016$ (Haze-I) & $10.6 \pm 2.2$ & This study \\
Mountain site & $4-5 / 11 / 2016$ (Haze-II) & $27.9 \pm 4.7$ & This study \\
Beijing city & $16-19 / 1 / 2010$ & 4.5 & Zhao et al. (2013) \\
Jinan city & $13-23 / 12 / 2014$ & 5.5 & Chen et al. (2017) \\
Tianjin city & $10-12 / 1 / 2013$ & 5.3 & Han et al. (2014) \\
\hline
\end{tabular}




\section{References}

Chen, S., Xu, L., Zhang, Y., Chen, B., Wang, X., Zhang, X., Zheng, M., Chen, J., Wang, W., Sun, Y., Fu, P., Wang, Z., and Li, W.: Direct observations of organic aerosols in common wintertime hazes in North China: insights into direct emissions from Chinese residential stoves, Atmos. Chem. Phys., 17, 1259-1270, https://doi.org/10.5194/acp-17-1259-2017, 2017.

Han, S., Wu, J., Zhang, Y., Cai, Z., Feng, Y., Yao, Q., Li, X., Liu, Y., and Zhang, M.: Characteristics and formation mechanism of a winter haze-fog episode in Tianjin, China, Atmos. Environ., 98, 323-330, https://doi.org/10.1016/j.atmosenv.2014.08.078, 2014.

Zhao, X. J., Zhao, P. S., Xu, J., Meng, W., Pu, W. W., Dong, F., He, D., and Shi, Q. F.: Analysis of a winter regional haze event and its formation mechanism in the North China Plain, Atmos. Chem. Phys., 13, 5685-5696, https://doi.org/10.5194/acp-13-5685-2013, 2013. 